\title{
Participaç̃̃o, empreendedorismo e autogestão: uma nova cultura do trabalho?
}

JAGOB GARLOS LIMA

\section{Resumo}

Este artigo busca discutir mudanças na cultura do trabalho, decorrentes dos processos de flexibilização das últimas décadas, nas quais a ênfase na maior autonomia do trabalho vem acompanhada paradoxalmente de maior subordinação, sob a égide do empreendedorismo. Para isso, discutimos o ideário da participação nas empresas e a utilização do autocontrole e autogestão nas equipes de trabalhadores; na reinterpretação da informalidade como empreendedorismo e do trabalho associado em cooperativas sob a égide do empreendedorismo social. A idéia de participação e responsabilização, mesmo em distintas configurações organizacionais, apresenta-se como caminho para os trabalhadores obterem maior autonomia e emancipação no quadro referencial do próprio capitalismo ou no quadro de uma outra economia, que mesclaria ou conviveria de forma plural com formas distintas de produção e de propriedade. Esse ideário, com distintas gradações passa a compor uma cultura do trabalho, marcada pelos valores do chamado capitalismo flexível: individualização crescente e o mercado como balizador das relações sociais.

Palavras-chave: Empreendedorismo. Informalidade. Autogestão. Economia solidária. Cultura do trabalho.

\footnotetext{
* Departamento de Sociologia. Universidade Federal de São Carlos.
} 


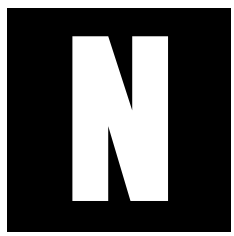

o contexto das transformações produtivas das últimas décadas, os conceitos de participacionismo, empreendedorismo e associativismo passaram a ser discutidos dentro da perspectiva das mudanças nas formas de gerenciamento da força de trabalho e das relações de assalariamento, da precarização das relações de trabalho, do crescimento da informalidade e de alternativas ao desemprego. Embora representando propostas e situações distintas, complementam-se, e, às vezes, confundem-se, no quadro de referência dos interesses empresariais, das políticas públicas voltadas ao mercado de trabalho e geração de renda, e mesmo, dos movimentos dos trabalhadores em busca de melhores condições de vida e trabalho. Mais que uma mudança nas formas de organização de produção, temos mudanças na percepção do trabalho, dos valores a ele vinculados, do seu caráter coletivo e de suas possibilidades enquanto formadores de identidades e projetos sociais.

Este artigo busca discutir essas mudanças que não são apenas nas relações ou na organização do trabalho, nas quais a participação e autonomia do trabalhador têm preponderância nas narrativas justificadoras do novo "espírito do capitalismo" (BOLTANSKI; CHIAPELLO, 2009), mas também em valores compartilhados pelos trabalhadores, que incorporam, resistem, reelaboram e atuam, a partir dessas transformações estruturais.

Entre essas mudanças, destacamos a valorização do conhecimento do trabalho pelo trabalhador e sua funcionalidade para o capital, no sentido do aumento da produtividade, como também, para o trabalho em sua potencialidade transformadora em termos de autonomia e emancipação, mas com forte viés individualista. Participação como autocontrole e autogestão de equipes nas empresas; autogestão empreendedora em empresas de propriedade coletiva como cooperativas e a informalidade em sua "positividade", representada pelo empreendedorismo dos pequenos 
produtores. Sai de cena, ou pelo menos perde visibilidade, o projeto do trabalho coletivo enquanto possibilidade de transformação social, sendo substituído por alternativas de menor alcance, na qual esse projeto permanece ao lado de outros.

Entretanto, fica a questão de como o trabalhador incorporou o ideário propagado em décadas de flexibilidade na produção, no consumo e na gestão da força de trabalho e no qual o mercado, em tese, aparecia como absoluto. Período no qual o então chamado neoliberalismo ${ }^{1}$ recolocava a ação individual como única possibilidade emancipadora e a perspectiva coletiva como burocrática, autoritária e ultrapassada. Em que medida, esse discurso fortemente ideológico tem sido incorporado pelos trabalhadores e integrado ao que poderíamos chamar de cultura trabalho?

$\mathrm{Na}$ busca de respostas a essa questão, ou pelo menos de hipóteses explicativas, partimos da discussão sobre o conceito de participação no quadro de referência do toyotismo, no qual o envolvimento no trabalho pressupõe o vestir a camisa da empresa e aceitar uma cultura empresarial na qual autonomia, confiança, trabalho em equipe e autogestão controlada, constituem-se em valores disseminados e utilizados como forma de aumentar a competitividade empresarial. Essa autonomia pressupõe conciliar gestão da produção pelos trabalhadores em seus aspectos positivos de conhecimento acumulado e sua responsabilização na organização do e no processo de trabalho, de forma restrita e consultiva sob controle gerencial. O discurso empresarial enfatiza, ainda, um perfil de trabalhador marcado pela flexibilidade frente às mudanças, investindo em sua formação permanente e aberto a novos desafios, um empreendedor de si mesmo que garantiria, dessa forma, sua empregabilidade e permanência num mercado em contínua transformação.

1 Período aproximado entre os anos 1980 e início da década de 2000 marcados por políticas de liberação econômica e retração do Estado como agente regulador das relações capital-trabalho. 
A valorização do trabalho autônomo empreendedor reinterpreta igualmente o trabalho informal, destacando seu potencial criador vinculado à predisposição individual ao risco e à inovação. Sinônimo de flexibilidade, abrange desde consultores altamente qualificados, com contratos temporários e/ou por projetos, ou sem contrato algum, chegando até os trabalhadores em atividades precárias como ambulantes, camelôs e outros que sobrevivem na precariedade.

Essa perspectiva se espalha, mesmo nas propostas coletivistas por excelência que são as cooperativas e empresas autogestionárias. Nestas, o caráter empreendedor, agora a serviço do coletivo, explicaria o sucesso de empreendimentos nos quais os trabalhadores autogeririam efetivamente suas atividades, retomando a ideia de "projeto" emancipatório, não só na criação de uma alternativa ao desemprego e da precarização das relações de trabalho, mas também, de uma "outra" economia, na qual o trabalho teria precedência sobre o capital.

\section{Uma sociologia cultural do trabalho?}

A utilização do conceito "cultura do trabalho" é pouco usual em Sociologia. Talvez pela própria dificuldade e complexidade do termo cultura, com diversas significações possíveis. Não temos como pretensão aprofundar uma discussão acerca do conceito de cultura, aceitando sua definição a partir da convergência dos sentidos atribuídos ao termo pela Sociologia e Antropologia, como um sistema de significações envolvidas nas formas de atividade social, um conjunto de categorias e planos de ação compartilhados por um grupo, ou grupos, que não apenas definem coletivamente o mundo, mas o gerem e organizam. Trata-se de uma arena onde se trocam e enfrentam elementos conflitivos, como o escrito e o oral, o dominante e o dominado, fraturas e oposições (BECKER, 2008; THOMPSON, 2008). 
Trabalho significa o conjunto de atividades realizadas pelo homem para viver, sejam elas para a subsistência material, sejam para as necessidades do espírito tal como indicado por Marx. Todas as sociedades compreendem o significado de trabalho, variando historicamente seus determinantes em termos de estrutura da própria sociedade, à centralidade maior ou menor na formação de identidades sociais, tal como acontece no capitalismo. Se aceitarmos que os homens compartilham os significados das atividades sociais que realizam, definindo e interpretando o mundo em que vivem, podemos afirmar que o mesmo acontece no trabalho, no qual as relações sociais atuam no sentido de ampliação das capacidades humanas de produzir, ao mesmo tempo em que ampliam as formas de exploração e dominação dessas mesmas capacidades.

Recuperando a cultura do trabalho na história da Sociologia, Harper e Lawson (2003) destacam a abordagem dos clássicos da disciplina: Marx ao referir-se à relação capital-trabalho e à constituição da sociabilidade capitalista, não apenas no conflito estrutural entre classes, mas a própria formação das classes com suas formas de vida específicas e as condições de vida e trabalho em comum na formação de identidades coletivas e projetos políticos: Weber, na definição cultural da mudança do trabalho a partir do protestantismo e de sua ética do trabalho duro como fator de valorização perante Deus e de melhoria na terra, e como este passa a dirigir nossas vidas. Em Durkheim, a divisão do trabalho se constitui na chave para a compreensão das mudanças na sociedade, nas solidariedades existentes na sociedade tradicional e a passagem para a sociedade moderna, seu enfraquecimento e a anomia como resultado. Na tradição norteamericana destacam-se os estudos da Escola de Chicago que, em certa medida, inauguram os estudos culturais do trabalho, em autores como Mayo ([1933] 1952) ao analisar os grupos informais no trabalho fabril; Hughes (1972) e as ocupações que reivindicavam o status de profissões; 
Roy (1952) ao estudar como os trabalhadores de uma fábrica metalúrgica estabeleciam informalmente as taxas de produção e pressionavam ou "botavam na linha" os que produziam mais, além dos arranjos informais na utilização do tempo e as brincadeiras dentro do espaço de trabalho².

As formas de resistências próprias das culturas de trabalho assumem grande visibilidade com a produção inglesa sobre história social dos trabalhadores, com Hobsbawn (1987), Thompson (2008), Williams (1992), Hoggart (1998), Willlis (1991) que apontam para a construção de sociabilidades e identidades sociais a partir da experiência cotidiana dentro e fora das fábricas.

Na produção francesa, destacamos o estudo de Linhart (1986) sobre uma greve numa fábrica de automóveis, em pleno fordismo, na qual grupos de trabalhadores imigrantes se articulavam na linha de montagem para enfrentar os tempos e ritmos impostos, as reações combinadas pelos grupos, a direção da fábrica utilizando o fator "étnico" como controle, entre outras formas culturais que poderíamos agrupar na dualidade dominação e resistência; a pesquisa de Bouvier (1989) sobre o cotidiano e as representações no universo de trabalho de trabalhadores do metrô de Paris; Beaud e Pialoux (2009), sobre as mudanças na condição operária com o "pós" fordismo e a reestruturação da indústria automobilística e o desmonte do trabalho coletivo, da solidariedade de classe e da própria condição de classe.

No Brasil, a cultura do trabalho aparece em numerosos trabalhos sobre formação de classe, trajetórias de trabalhadores formais e informais, no estabelecimento de uma ética do trabalho, gênero, subjetividade ope-

2 Estudos esses que nos remetem a Taylor (1982) que, em seus "Princípios de administração científica", reclamava da resistência dos trabalhadores às tentativas de utilização de técnicas de racionalização do trabalho a partir dos grupos informais dentro do espaço fabril e pressão do coletivo sobre os trabalhadores que se dispusessem a trabalhar conforme essas técnicas. 
rária, família, redes sociais no mercado de trabalho, identidades sociais e outros que refletem a expansão do campo da Sociologia do trabalho para estudos da cultura do e no trabalho ${ }^{3}$.

Focamos nossa discussão na relação cultura-relações de trabalho, a partir do eixo autonomia, gestão, heterogestão e autogestão. A cultura do trabalho abarca um conjunto de estratégias e atividades que se imbricam, complementam-se, diferenciam-se e, às vezes, se confundem com o que poderíamos chamar de cultura de classe ${ }^{4}$, do capitalismo, do assalariamento ${ }^{5}$, empresarial 6 , empreendedora, social empreendedora, na qual o trabalho configura fortemente as relações entre os atores. Nesse sentido, é composta de ideologias justificadoras e contra-ideologias, nas quais o mundo do trabalho tem sido ressignificado: formas de resistência e formas de consentimento à dominação; maior individualização nas relações de trabaIho, ao lado de formas de valorização do coletivo; novas proposições e interpretações do trabalho coletivo e de suas possibilidades; fim e retorno da ideia de projeto. Enfim, uma miríade de situações nas quais o trabalho continua fundamental na explicação do social e dos valores que justificam ou contestam a ordem vigente. Ao optar pelo eixo acima referido, enfatizamos

\footnotetext{
3 São numerosos os estudos que podem ser agrupados nessa perspectiva. Destacamos, entre outros, Leite Lopes (1988), Colbari (1995), Lima e Ferreira (1996), Itani(1997),Silva (2003), Guimarães, Agier e Castro(1995); Lima e Ferreira( 1996); Batalha, Silva e Fortes( 2004), Telles(2006). 4 Para uma discussão de culturas de classe tendo o trabalho como referência, veja-se Savage (2004). 5 Sobre cultura do assalariamento ou sociedade salarial, veja-se Castel (1998).

6 Por cultura empresarial, entendemos como Barbosa (2002), a organização simbólica do universo empresarial. Como se organizam o cotidiano das empresas, a ação coletiva e a mudança. Como os tipos de empresas são variados, poder-se-ia se falar de culturas empresariais, termo mais adequado para as comparações entre diversos tipos de empresa. Seria um tipo específico de cultura no capitalismo. A partir do final do século XX, esta extravasou a lógica do mercado e a empresarial, levando a lógica da eficiência eficácia, rentabilidade e qualidade para outras esferas da sociedade dentro do contexto neoliberal, a empresa assumindo as vantagens do capitalismo empreendedor em contraposição a culturas corporativas hierárquicas que não estimulam os integrantes a atuarem como sujeitos autônomos.
} 
a incorporação do discurso ideológico do novo capitalismo às relações de poder e autoridade no trabalho, tal como caracterizado por Sennett (2006) ao se referir à cultura do novo capitalismo, marcada pelos projetos de curto prazo, pelo desapego, pela instabilidade e pela precarização da vida.

\section{O espírito do capitalismo e a cultura do empreendedorismo}

Ao discutir o "espírito do capitalismo", recuperando o termo de Benjamin Franklin, Weber (1981) destacou a criação de um novo tipo de homem vinculado às novas formas de produção. Esse novo homem teria o caráter empreendedor, de trabalho constante, decorrente de uma cultura própria no Ocidente, que explicaria o florescimento do capitalismo em comparação a situações de mercado que não configuraram um novo tipo de organização econômica. O protestantismo teria favorecido o desenvolvimento de uma nova ética que caracterizaria esse novo espírito do tempo, na qual, o trabalho duro seria recompensado, seja em termos materiais pelo acúmulo de riquezas, seja na relação com Deus que valorizaria o trabalho. Essa ética teve, no calvinismo, um homem voltado ao trabalho racional, regular, interpretado como obediência a um mandamento divino e o surgimento de uma cultura na qual, subjetivamente, o trabalho foi incorporado como valor e passou a orientar as condutas humanas.

O novo homem do capitalismo foi discutido por Schumpeter (1982), através da figura do empresário, com seu caráter inovador e empreendedor, distinto do conjunto da população e elemento fundamental de qualquer sociedade. O empreendedor seria o inovador combinando diversos fatores de produção como: trabalho, terra, capital, conhecimento e capital social na produção de bens e serviços para um mercado relativamente competitivo dentro de contextos determinados. Difere do capitalista e, 
enquanto tal, não se constitui nem em profissão, nem uma condição duradoura e nem classe, ainda que o êxito da atividade empresarial o leve a determinadas posições de classe. O empresário não seria parte necessariamente da burguesia, estando presente em vários setores sociais, a partir de indivíduos que incorporariam essa "psicologia" do empreendedor, marcada pela ambição social, engenhosidade, criação de novos produtos e empresas, bem como de oportunidade ou necessidade (MARTINELLI, 2009).

Da mesma forma, o empresário se diferenciaria do que chama de "mero" administrador. A diferença entre o primeiro e o segundo é que aquele escaparia do "fluxo habitual" de todo indivíduo que age racionalmente a partir da segurança dada pela aptidão e experiência que caracterizariam o segundo que, ao defrontar-se com a inovação, precisará de orientação. O empresário, ao contrário, seria caracterizado pela liderança ao nadar contra a corrente rotineira. O sucesso dependeria igualmente de fatores subjetivos como a intuição, a capacidade de ver as coisas de uma forma que posteriormente evidencie estar correta. Assim, o tipo empresarial de liderança pôde ser encontrado tanto no capitalismo, no socialismo ou mesmo numa tribo primitiva e é caracterizado por "conduzir" os meios de produção para outros canais, ou seja, para a inovação, fazendo com que os concorrentes o acompanhem. Essa liderança se dá à sua revelia, uma vez que não busca convencer as pessoas da conveniência de determinadas atitudes, mas arrasta atrás de si os outros produtores.

Dessa forma, o comportamento do empreendedor não se enquadra numa perspectiva racional, utilitária de meios de fins; pressupõe a incorporação de fatores subjetivos como força de vontade, motivação, ou seja, o sentido atribuído à conduta, tal como Weber caracteriza a ação social. Constitui-se num elemento cultural no qual os indivíduos não apenas definiriam o mundo, mas o gerenciariam, através de estratégias e atividades coordenadas (HARPER; LAWSON, 2003). 
A relação entre empreendedorismo e individualismo, marca do espírito do capitalismo aparece nas propostas de organização do trabalho do chamado período taylorista-fordista ${ }^{7}$, de forma contraditória. Neste, as empresas buscam a negociação individual para enfrentar o coletivo de trabalhadores e seu potencial belicoso. A "gerência científica" propõe a seleção a partir de critérios racionais, o homem certo para o lugar/atividade certa, contratos individualizados e subordinação total à gerência. É a separação radical do pensar-fazer, da hierarquização das estruturas de cargos, da fragmentação do trabalho em atividades simples e repetitivas. Desestímulo, reações informais e organizadas à intensificação do trabalho se tornam a conseqüência. Podemos afirmar que é o momento da consolidação do operário-massa, com as grandes concentrações operárias, fortes mobilizações coletivas contra a intensificação do trabalho, redução da jornada, melhores condições de trabalho e maiores salários, além de bandeiras políticas de transformação social que entram em declínio com a reestruturação dos anos $70^{8}$.

O toyotismo ou pós-fordismo, como proposta de organização da produção e do trabalho romperia com a rigidez corporativa, individualizando mais o trabalhador, a partir da noção de participação, competitividade, metas a serem atingidas, levando a uma fragmentação crescente do coletivo de trabalhadores, individualizando o ambiente de trabalho. A

7 Apesar dos estudos e experiências de Taylor e Ford se referirem à década de 1910, a aplicação de suas propostas na organização do trabalho e na própria sociedade, segundo os economistas da escola francesa de regulação, será no período pós-segunda guerra mundial e na crise do petróleo de 1973. Veja-se Harvey (1993).

8 Harvey (1993) defende que o sindicalismo europeu no período (1950-1973) teria trocado uma combatitividade "revolucionária" por uma de inserção ao sistema capitalista, através da integração das massas operárias à sociedade de consumo e o desencanto com o modelo socialista do leste. Na década de 60 essa combatitividade retornaria com as ocupações de fábricas e bandeiras de autogestão que indicariam o esgotamento do modelo taylorista-fordista. Para Boltanski e Chiapello (2009) esse período caracterizado pela consolidação do capitalismo industrial, seria o "segundo" espírito do capitalismo, em continuidade ao capitalismo inicial marcado pelo novo homem apontado por Weber. 
"autogestão controlada" utiliza o trabalhador contra o trabalhador, a diminuição da produtividade é responsabilizada individualmente, as estratégias individuais de sobrevivência no emprego substituem as coletivas por conquistas para toda a categoria. Essa individualização recoloca a autonomia do trabalhador e seu caráter empreendedor dentro do processo produtivo. A diversificação de formas de contrato, a redução dos contratos por tempo determinado e a subcontratação, de forma tendencial, apontariam para uma retomada do indivíduo empreendedor como o homem do terceiro espírito do capitalismo (BOLTANSKI; CHIAPELLO, 2009), em contraposição à subordinação do assalariamento.

\section{Participacionismo, autocontrole e autogestão}

O debate sobre fordismo e toyotismo (ou pós-fordismo), marcaria a chamada crise da sociedade salarial, caracterizada pela regulamentação pelo Estado das relações capital-trabalho e a incorporação de direitos sociais vinculados ao contrato de trabalho formal. A regulamentação dessas relações decorreria da incapacidade do mercado em organizar a sociedade, dada à irracionalidade de seu funcionamento. As diferentes formas de inserção dos indivíduos na produção, sua formação e capacitação para enfrentar os desafios de um ambiente competitivo provocam grande desigualdade social e, por consequência o acirramento dos conflitos sociais. O Estado seria o agente mediador dos conflitos e atenuador das diferenças, propiciando redistribuição da riqueza social e controlando os ímpetos destrutivos do mercado. O capitalismo regulado teve, no período fordista, seu apogeu e passou a ser atacado com a crise de acumulação dos anos $70^{9}$ e a reestruturação econômica que se seguiu. Soma-se a isso

9 Sobre a crise, veja-se Harvey (1993), Castells (1999). 
o fim dos Estados socialistas do leste europeu que colocou em questão as ideologias coletivistas de mudança social. A implementação de políticas de abertura econômica como solução para a retomada do crescimento, estabeleceu uma tendência ao enxugamento do papel do Estado no papel de preservar a ordem política e econômica, desregulamentando e privatizando as atividades sob seu controle e reduzindo os gastos sociais. Esse modelo conhecido como neoliberal, perdurou até a crise dos mercados de 2008, sendo que, a partir de então, retomou-se lentamente o debate sobre a importância do Estado no planejamento econômico e social.

O retorno "neoliberal" teve como uma de suas propostas a desregulamentação dos mercados de trabalho e objetivava a redução de custos com obrigações sociais vinculadas aos contratos de trabalho, assim como a flexibilização da utilização da força de trabalho adequando-a às necessidades da produção.

A rigidez do modelo de produção fordista, substrato da regulamentação, foi substituída pela flexibilidade da produção, da organização e gestão do trabalho, tendo como referência o toyotismo e a revalorização do conhecimento do trabalhador, sua desespecialização, seu envolvimento e participação no processo de trabalho. Esse "participacionismo" tornase fundamental no aumento da produtividade, pois conhecendo melhor o modo como o trabalho é executado, pode sugerir mudanças em sua execução para evitar desperdícios, "tempos-mortos", aumentando a responsabilização sobre o trabalho realizado.

O toyotismo ocidentalizado (ou em sua versão norte-americana) abandonou algumas características do modelo, como a estabilidade dos trabalhadores que pressupunha contratos vitalícios ou estáveis, destacando apenas a questão da flexibilização interna, cuja organização é a dos processos de produção e dos contratos de trabalho e a flexibilização externa, de fornecedores especializados e externalização de partes da 
produção. Enfim, soluções voltadas à redução de custos. Com relação à utilização da força de trabalho, a flexibilização altera os termos contratuais, introduzindo novas formas de utilização do tempo, ou seja, tempo parcial, determinado por tarefas, por empreita, por projetos e formas correlatas, com remuneração progressivamente desvinculada de obrigações outras que não as do pagamento do trabalho realizado.

Discutindo a empresa enxuta, forma por excelência da reestruturação flexibilizada, Boltanski e Chiapello (2009), apontam para caráter reticular dessa empresa e o processo de reengenharia pela qual passou. A imagem típica dessa empresa seria formada por núcleo enxuto, rodeado por fornecedores diversos, serviços terceirizados, prestadores de serviço e trabalhadores temporários. Os trabalhadores do núcleo, por sua vez, deveriam ser organizados por equipes pluridisciplinares que teriam uma coordenação e não, uma chefia. Essas equipes seriam compostas também pelos fornecedores, clientes, consultores e especialistas externos que funcionariam, em espaços distintos, situação esta possibilitada pelas tecnologias informacionais. Comporiam a equipe ideal, centrada nos desejos do cliente e espaço da autogestão e do autocontrole dos trabalhadores (p. 103).

A cultura da empresa, o sentido compartilhado, pressupõem a adesão de todos, todos sabendo o que fazer, sem ninguém que precise mandar. Entretanto, pressupõe também uma direção firme, possibilitando o pessoal autogerir-se. Com isso, a confiança torna-se um elemento central da autoridade, as lideranças se impõem pelo carisma, por competências, pelas redes sociais que estabelecem e não mais por hierarquias rígidas.

Para os trabalhadores, essa "autogestão" significa o autocontrole que garante sua permanência na equipe. A interiorização da cultura empresarial pressupõe o envolvimento pessoal, motivação, o vestir a camisa, marcado pela participação. Os operários tornam-se operadores, encarregando-se de outras funções como controle de qualidade e manutenção. As 
mudanças semânticas nos cargos e hierarquias inculcam uma cultura empresarial que, para ser eficaz, pressupõe adesão, sua transformação numa cultura de trabalho na qual esses valores normatizem o comportamento.

O trabalho autônomo é valorizado como ideal pelas empresas que passam a dispor da força de trabalho, apenas quando necessitam. O trabalhador, empresário e patrão de si mesmo, torna-se responsável por sua reprodução social, pagando por sua conta, taxas e impostos para ter acesso a serviços sociais, sejam estatais, sejam privados. Para sobreviver no mercado, depende ainda da busca de formação e atualização contínua, adaptabilidade às novas tecnologias, capacidade de inovar e se mostrar atento às mudanças, enfim, tornar-se flexível, aberto aos novos desafios.

Segundo Barbosa (2002, p. 38), esta cultura caracterizaria uma forma altamente individualizada de capitalismo, na qual, a atividade econômica privilegia as virtudes individuais que impulsionam a criação de riquezas como ambição, autonomia e empreendedorismo, elementos fundamentais a essa cultura. Entretanto, a ideia de participação tornou-se apenas "stock options" e não vozes efetivas que participam de fato da gerência. O autodesenvolvimento e o auto-enriquecimento deságuam no discurso da empregabilidade, responsabilização do trabalhador por um lado, e desresponsabilização das empresas no desenvolvimento de seus recursos humanos, por outro (p. 47). O trabalhador, mesmo assalariado, não se apresenta mais apenas como o possuidor de sua força de trabalho com capacidades pré-determinadas, impostas pelo empregador, mas como um produto que continua a se produzir, torna-se um empreendedor individual, gerindo sua carreira como uma pequena empresa (GORZ, 2005) ${ }^{10}$.

10 Nessa discussão, Gorz (2005), utiliza como referência Yan Moulier-Boutang, "La troisième transiction du capitalisme" in Vers, um capitalisme cognitif, organizado por Christian Azais, Antonella Corsani e Patrick Dieuaude, Paris, L'Harmattan, 2000 e Pierre Levy, "World Philosophie", Paris, Odile Jacob, 2000. 
Essas mudanças geralmente concentram-se em grandes empresas, com investimentos tecnológicos e organizacionais significativos que, de certa forma, estabelecem mais os parâmetros do debate do que propriamente a aplicação das teorias. Fora dessas, prevalece uma infinidade de formas organizacionais que incorporam parcialmente tendências e modas variadas funcionando mais no erro e acerto do que propriamente em inovações. Nestas, questões como participação, autonomia, qualidade, compõem mais o ideário empresarial do que a prática cotidiana onde permanecem formas tradicionais de organização do trabalho, tayloristas e pré-tayloristas.

\section{Empreendedorismo, informalidade e empregabilidade}

Polêmico desde sua origem, o conceito de informalidade aqui entendida como trabalho não regulamentado e localizado de forma majoritária em setores de baixa produtividade e rentabilidade como a pequena produção familiar, atividades comerciais ambulantes e outras voltadas à subsistência, retorna ao debate no final dos anos 80, sob a égide da acumulação flexível e suas possibilidades explicativas na compreensão dos mercados de trabalho no capitalismo periférico. Seu surgimento e utilização na década de 70 buscavam entender uma possível dualidade existente entre o formal e o informal em economias em processo de industrialização. Nestas, o primeiro representaria a modernidade capitalista do assalariamento regulamentado, sendo limitado em termos de dimensão do mercado existente, e o segundo como o contingente de trabalhadores fora desse mercado e suas estratégias de sobrevivência através de prestação de serviços pessoais, pequenos negócios informais e atividades descobertas pela regulamentação. Esse dualismo apareceu de formas distintas, seja entre moderno e atrasado (marginal), seja como complementar, desigual e combinado - faces de uma mesma moeda que 
caracterizaria a acumulação capitalista em países periféricos: o informal garantiria a reprodução ampliada do capital, mantendo um largo exército industrial de reserva que garantiria a permanência de baixos salários para a indústria e o setor moderno. Ou ainda a complementação de mercado no qual a informalidade possibilitaria formas alternativas de distribuição dos produtos industrializados. Os custos da regulação seriam compensados pela informalidade, sem regulamentação alguma.

A interpretação "neoliberal" muda o enfoque, apontando não a falta, mas o excesso de regulamentação estatal na América Latina, como causa da informalidade. Para De Soto (1987), tendo como referência a sociedade peruana, a informalidade revelava o caráter empreendedor do trabalhador latino-americano, sufocado por um Estado centralizador.

É desse período também, o crescimento da informalidade nos países centrais, interpretado como consequência da reestruturação econômica, produto da desindustrialização, da terceirização, do aumento do desemprego e crescimento da imigração. Do caráter de atividade própria de países subdesenvolvidos, a informalidade começou a ser analisada dentro das redes étnicas de integração de imigrantes, legais e ilegais, e formas de rebaixamento de custos de atividades industriais e comerciais nas grandes cidades. A informalidade foi incorporada ao trabalho não estandardizado, ilustrado pelas formas de contrato por tempo parcial, temporário, autônomo, em contraposição ao padrão do assalariamento regular, representado por contratos por tempo indeterminado, com direitos sociais acoplados, etc. (PORTES; CASTELLS, 1988; PORTES, 1994).

O informal, visto como autônomo, ou com baixa regulamentação, tornou-se um produto do capitalismo flexível, com as rápidas mudanças tecnológicas e informacionais e o alto grau de mobilidade do capital e da força de trabalho que borram as fronteiras geográficas e eliminam as barreiras tempo-espaço (HARVEY, 1993). 
Essa nova informalidade se multiplica com a utilização de redes de subcontratação em diversas partes do mundo. Em países periféricos, a informalidade juntamente com formas não padronizadas de contrato de trabalho (entendidas no arcabouço do assalariamento formal) torna-se atrativa para investimentos industriais, com grandes incentivos governamentais e passam a ocupar uma força de trabalho sem tradição industrial ou de trabalho organizado, como por exemplo, as maquiladoras no México e na América Central e a produção industrial caracteristicamente de trabalho intensivo que se multiplicam nos países periféricos que propiciam trabalho barato e não organizado, logo, menores custos e mesmos riscos para o capital. Da mesma forma que assistimos à desindustrialização de áreas tradicionais, temos a inclusão de novos territórios à produção industrial e ao mercado globalizado.

Com isso, assistimos a uma espécie de des-demonização da informalidade, de sinônimo de subdesenvolvimento para sinônimo de desregulamentação, flexibilidade e mesmo de empreendedorismo.

O discurso do empreendedorismo acompanhou as reformas de Estado em países latino-americanos, com a privatização de empresas estatais, dos programas de demissão voluntária e dos programas de crédito para pequenos negócios. Além dos investimentos em tecnologia e inovação, programas de empreendedorismo foram implementados a partir dos anos 90 no Brasil, para pequenos negócios de baixo valor, com apoio estatal e paraestatal. O "empreendedorismo por necessidade" envolve pessoas com negócios de baixo valor agregado e com menor possibilidade de sobrevivência. Segundo o IBQP (Instituto Brasileiro de Qualidade e Competitividade) ${ }^{11}$, "a inclusão desse tipo de empreendimento - que representa em torno de oito milhões de pessoas no Brasil - é tida como

11 Instituto Brasileiro de Qualidade e Competitividade. Disponível em: <http://www.gembrasil.org.br>. 
uma possibilidade de mudança no atual quadro econômico e social do País." Podemos exemplificar essa situação, a partir de clusters industriais do setor do vestiário (calçados e confecções), distribuídos por várias regiões do país nas quais convivem fábricas e oficinas formalizadas, com uma maioria informal que garante a competitividade dos custos das mercadorias produzidas. Nessas situações, o "abrir seu próprio negócio", geralmente uma pequena oficina, torna-se o objetivo de grande parte dos trabalhadores envolvidos (LIMA; SOARES, 2002; SOUSA LIMA, 2009).

O trabalhador do informal, mais que um excluído do mercado, seria então um empreendedor por necessidade. Depende de seus investimentos no negócio/atividade que desenvolve para sobreviver, de sua predisposição em inovar, trabalhar duro, como probabilidade de sucesso. Transformar uma situação de mercado desfavorável, em seu contrário. Revendo o conceito, Machado da Silva (2003) discute sua pertinência, dada sua imprecisão e generalização original e sua substituição por empreendedorismo e empregabilidade talvez mais adequados ao capitalismo reestruturado. Entretanto, essa substituição não elimina o caráter explicativo, que, mesmo com todas as imprecisões, o termo informalidade carrega.

Isto porque, mesmo referindo-nos a uma pretensa crise da sociedade salarial, essa crise deve ser matizada. Embora tenha-se reduzido sua abrangência e seu caráter constitutivo das relações capital-trabalho, essa redução se refere a contratos por tempo indeterminado e com direitos sociais, ou vantagens previstas neste contrato. Multiplicam-se contratos por tempo determinado, tempo parcial e outras formas de contrato que, mesmo precários, continuam formais.

Deslocamentos industriais para países periféricos, para outras regiões de um mesmo país, em diversas situações, mantêm a relação salarial, variando os custos em função, por exemplo, dos incentivos fiscais recebidos pelas empresas e pelo trabalho não organizado e utilizando fartamente redes de 
subcontratação. No caso brasileiro, grande parte das cidades que recebem novos investimentos industriais, fora das áreas tradicionais, mantém o salário mínimo regulamentar, por causa da fraqueza ou mesmo inexistência de sindicatos. Quando os sindicatos são formados e passam a reivindicar, as empresas se deslocam para outras cidades, aproveitando-se da guerra fiscal entre cidades e regiões, utilizando espaços e infra-estrutura subsidiados pelo Estado em vários níveis. Dado aos baixos investimentos, quando os incentivos são reduzidos, as empresas encaixotam suas máquinas e as transferem para outros espaços. Para os trabalhadores, resta o desemprego.

No Brasil, a flexibilização da legislação trabalhista no Brasil começou com a implantação do FGTS em 1966, que eliminou a obrigatoriedade de a empresa pagar uma indenização por demissões. Contrariamente, com a legislação de alguns países europeus, a empresa não precisa consultar os sindicatos quando vai realizar cortes, o que desonera sua formalização (CAMARGO, 1996). No governo Fernando Henrique Cardoso, foram feitas tentativas de flexibilização que afetaram funcionários públicos com formas de quebra da estabilidade e a possibilidade de contratos temporários, mas não houve maiores alterações da Consolidação das Leis do Trabalho que impactassem, pelo menos formalmente, as relações de trabalho.

Outro dado relevante é que a contratação de trabalhadores temporários pode ser formal ou informal, conforme o setor e o tamanho da empresa, como também a região em que esteja instalada. Esses condicionantes significam maior ou menor visibilidade da empresa ou atividade econômica, assim como a necessidade de formalização para ter acesso a crédito bancário, acesso a mercados e, por consequência, passam a ser objeto de maior fiscalização de órgãos governamentais. Isto a torna mais adequada por envolver menores riscos de confronto com órgãos fiscais do Estado, da Justiça do Trabalho ou o Ministério Público. 
A informalidade também tem variado conforme a maior ou menor expansão da economia brasileira. Se, em 1998, os índices de informalidade representavam 56,89\% da força de trabalho ocupada, em 2008 esse número passou para 49,88\%, uma redução de $7 \%$, segundo dados da PNAD elaborados por Leite (2009).

Mais do que indicar uma tendência à informalização, a flexibilização aponta também para novas institucionalizações no mercado de trabalho: da pessoa jurídica, na qual o trabalhador individual é contratado como se fosse uma empresa; do crescimento dos autônomos principalmente para trabalhadores mais qualificados e profissionais que prestam serviços ou trabalham como consultores onde antes integravam os quadros de empresas como advogados, psicólogos, dentre outros; de estagiários; de cooperativas formadas por trabalhadores para as redes de terceirização que, muitas vezes, atuam na informalidade.

Novas categorias de trabalhadores como os das tecnologias de informação surgem num contexto de fragilização do assalariamento e, dadas suas condições específicas, decorrentes da imaterialidade de sua produção, complexificam essa discussão. O conhecimento como valor intrínseco à produção, conhecimento este não necessariamente acadêmico, mas produzido no intercâmbio de informações, a rapidez das mudanças e a atualização permanente colocam desafios, tanto na autonomização proposta para esses trabalhadores, quanto na institucionalização de seus contratos. Constituem-se enquanto especialidades, ocupações ou mesmo profissões a partir das novas tecnologias, sendo flexíveis em sua origem. Como autônomos trabalham por projetos para uma empresa ou mais, podem trabalhar em casa ou estações de trabalho, uma vez que necessitam apenas estar ligados na internet. A desterritorialização aqui pode ser absoluta, uma vez que o trabalho é todo realizado virtualmente. A empregabilidade é dada pela capacidade de formação e atualização permanentes, 
o que pressupõe o acesso aos novos instrumentos disponíveis na web e o desenvolvimento de produtos que se constituem num desafio constante. Para esses trabalhadores, nem sempre interessa um contrato regular de trabalho por tempo indeterminado, pois, muitas vezes, este é visto como empecilho à atualização.

Uma precariedade intrínseca acompanha a formação dessas categorias que, no geral, escapam dos limites impostos a jornadas de trabalho extensas, descanso e outros benefícios. A cultura compartilhada é do individualismo, quase do predador em busca da inovação permanente. Ao mesmo tempo, o desenvolvimento de software é compartilhado na rede, elemento de divulgação e mesmo de possibilidade de conquistas de novos contratos, o que torna essas redes sociais virtuais, uma necessidade (RIBEIRO, 2009). Redes sociais que eliminam a sociabilidade construída num cotidiano de trocas presenciais.

$\mathrm{Na}$ outra ponta das novas categorias decorrentes das novas tecnologias informacionais, temos o telemarketing e uma taylorização da atividade devidamente atualizada em termos de controles digitalizados, trabalho intenso, repetitivo e mecânico, mas contratos formais dentro da CLT. Aqui a autonomia do trabalho aparece na capacidade do trabalhador em conseguir êxito numa cobrança ou venda de algum produto por telefone. Autonomia bem relativa, pois tem que observar um conjunto de procedimentos que é monitorado digitalmente (BRAGA, 2009; ROSENFIELD, 2009; VENCO,2009)

Há, então, diversos tipos de empreendedores: autônomos, com distintos graus de formalidade, necessidade e precariedade. Desde o trabaIhador sem qualificação alguma que vive de expedientes ou vendendo quinquilharias nas ruas, ao trabalhador vinculado às novas tecnologias informacionais, trabalhando de forma desterritorializada, por projetos. De 
um extremo a outro, uma precariedade constituinte na ausência de controles à intensificação do trabalho e ao acesso a benefícios sociais.

\section{O empreendimento coletivo: autonomia, autogestão e mercado}

Tal como o trabalhador autônomo, o trabalho associado em cooperativas é revalorizado numa dupla perspectiva: para os trabalhadores, pela autonomia e democratização que, em tese, as empresas autogestionárias adotam, possibilitando o fim da relação de subordinação do trabalho assalariado, além de ser uma alternativa em tempos de desemprego crescente para as empresas, pela sua desobrigação com a gestão da força de trabalho. Algumas empresas em processo de reestruturação incentivam seus trabalhadores a criarem cooperativas e trabalharem como terceirizadas para os antigos patrões. Outros enxugam setores, passando linhas de produção para os trabalhadores. As cooperativas radicalizariam alguns ideais participacionistas presentes no toyotismo: sendo ao mesmo tempo proprietários, gestores e trabalhadores, se envolveriam ao máximo no trabalho, aumentando a produtividade e reduzindo custos no trabalho.

Nas cooperativas, o trabalho perderia seu caráter genérico, heterônomo característico do assalariamento, para um trabalho enriquecido, autônomo, no qual o trabalhador passa a ser responsável pela produção. Entretanto, a autonomia no processo de trabalho, num contexto de capitalismo reticular, cria novas formas de subordinação no mercado, independente de a cooperativa estar em redes de subcontratação com empresas, ou possuir produtos próprios. O mercado possui um caráter determinante na sobrevivência da cooperativa, arrefecendo eventuais pendores anticapitalistas dos trabalhadores. 
Nessas situações, a autonomia pressupõe autocontrole do trabalhador da empresa reestruturada e "espírito empreendedor" na autogestão possível; torna-se, pois, condição da própria existência - a sobrevivência do negócio é a sobrevivência do trabalhador. Mesmo mantendo propostas de equidade e justiça social e de defesa da autogestão do coletivo, a empresa é um negócio e, como tal, deve ser gerido.

A autogestão em cooperativas de trabalhadores, uma bandeira originalmente dos trabalhadores visando maior autonomia e democracia no trabalho, tem sido igualmente reinterpretada ${ }^{12}$. Não exatamente como resultado de mobilizações operárias nas quais a bandeira da autogestão teria um caráter de transformação social ou um projeto de sociedade mais democrática, e sim, frente ao desemprego estrutural decorrente da reestruturação econômica. As cooperativistas passaram a ser vistas como alternativa possível através de ocupações de fábricas e sua recuperação sobre controle dos trabalhadores; cooperativas organizadas por trabalhadores, por entidades governamentais, ONGs, sindicatos visando o combate ao desemprego; formas alternativas de produção vinculadas a movimentos contra-culturais e mesmo por empresas, com o objetivo de enxugamento da produção a partir da terceirização de atividades.

12 Originárias no século XIX, no bojo do chamado socialismo utópico, as cooperativas foram pensadas e tentadas como empreendimentos, voltadas à autonomia dos trabalhadores frente ao capital. Polêmicas em sua origem, o debate no interior do movimento operário se radicalizou na dualidade reforma/revolução: as cooperativas representariam uma postura reformista, desviando a classe operária de seu objetivo principal, a luta pela revolução social, a partir da gestão de empresas por trabalhadores no mercado; numa perspectiva oposta, se constituiriam num ponto de partida dessa revolução, apontando para a efetividade da gestão operária dos meios de produção. Em 1905, com a criação da Associação Cooperativa Internacional, foram estabelecidos os princípios do cooperativismo, que, de certa forma, deram os parâmetros de funcionamento das cooperativas de trabalhadores. Dentre outros, podemos destacar a liberdade de adesão, a propriedade coletiva, a autogestão do trabalho e as decisões democraticamente discutidas e implementadas. Durante todo o século XX, em países como França e Itália, as cooperativas integraram a chamada economia social, tendo-se consolidado enquanto forma de organização econômica, embora periférica frente ao assalariamento dominante. Suas atividades abrangeram vários ramos, além do trabalho, tais como crédito, habitação, consumo, produção agrícola, etc. 
O debate atual sobre cooperativismo e economia solidária tem mantido na perspectiva de uma alternativa ao desemprego e sua efetiva sustentabilidade, que pressupõe discutir as relações com o mercado, sua incorporação, manutenção e reprodução. Para continuar como empresa, a cooperativa tem de estar atualizada tecnológica e organizacionalmente para ter ganhos de produtividade e manter sua competitividade, fatores estes que, por sua vez, podem comprometer a proposta de cooperativa em termos de gestão autônoma e democrática. A autogestão dos trabaIhadores constitui-se, nesse contexto, mais como um objetivo a ser alcançado do que propriamente uma forma efetiva de organização e gestão.

No Brasil, a partir da abertura econômica, várias cooperativas de trabaIho foram organizadas. Fábricas em situação falimentar foram recuperadas com o apoio de sindicatos, ONGS e de órgãos governamentais. Em 1994, com a formação da ANTEAG (Associação Nacional de Trabalhadores em Empresas Autogestionárias), surge o que poderíamos chamar de novo cooperativismo, em contraposição ao velho cooperativismo, existente no país e marcado pelas grandes cooperativas agrícolas organizadas empresarialmente. A diferença do novo estaria no compromisso político com os princípios da autogestão, autonomia e democracia do trabalho e voltada basicamente às cooperativas de produção, trabalho e geração de renda. Nesse mesmo período, numa perspectiva às vezes oposta ou contraditória, multiplicaram-se também cooperativas, organizadas ou apoiadas por empresas, sindicatos e Estado, para a terceirização industrial. É nesse período que se inicia o debate sobre cooperativismo autêntico versus falsas cooperativas que irá colocar o Ministério Público do Trabalho na fiscalização desses empreendimentos e fechamento de diversas unidades consideradas fraudulentas.

Nesse contexto, constitui-se e se fortalece o movimento de economia solidária, incorporando o cooperativismo como alternativa a uma sociedade mais justa e igualitária; um socialismo renovado, tendo como 
proposta a inclusão dos trabalhadores que estão fora do mercado, por causa da reestruturação, ou pelo processo histórico de marginalização. Diversas instituições de apoio à formação de cooperativas surgem no país como as ITCPs (Incubadoras Tecnológicas de Cooperativas Populares) em diversos campi universitários, para a incubação de cooperativas, voltadas a populações de baixa renda: cooperativas de reciclagem, de limpeza, de costura, de alimentação, artesanato, buscando a inclusão social. Diversas prefeituras e governos estaduais progressivamente criam suas próprias incubadoras. $\mathrm{O}$ movimento sindical, através da Central Única dos Trabalhadores, organiza a ADS - Agência de Desenvolvimento Solidário, voltada a empreendimentos autogestionários. Ao lado da pioneira ANTEAG, surge a Unisol, vinculada ao Sindicato dos Trabalhadores Metalúrgicos do ABC paulista, que assume caráter nacional na organização e apoio a cooperativas.

Tendo como objetivo a organização de uma economia popular e solidária, o movimento passou a apoiar empreendimentos caracterizados pela autogestão, independentes de se configurarem formalmente como cooperativas. Com a criação, em 2003, da Secretaria Nacional de Economia Solidária pelo Governo Federal, foi formalizada enquanto política pública. O movimento conta com o apoio e a participação de vários setores da sociedade civil como igrejas, sindicatos e universidades, em sua coordenação e na incubação de cooperativas, além dos órgãos governamentais como já citado.

No entanto, esse crescimento vem acompanhado das polêmicas presentes desde o início no movimento cooperativista. O apoio sindical, por exemplo, tem múltiplas facetas, que incluem a vinculação política aos princípios cooperativistas, mas com ênfases distintas, conforme o sindicato ou mesmo a central sindical: ora como possibilidade de democratização da propriedade e da gestão e observação dos princípios presentes na proposta, ora como uma empresa regular com gestão dos trabalhadores, 
mas pragmaticamente orientada para o mercado, ora combatidas como precarização do trabalho.

De forma geral, a multiplicação de cooperativas tem resultado de políticas de geração de renda, voltadas a populações excluídas do mercado de trabalho. Entre estas, destacam-se as cooperativas de coleta e reciclagem de lixo como exemplo de cooperativas sociais ou populares.

Entre os problemas enfrentados pela autogestão, no caso de fábricas recuperadas, encontram-se a obsolescência tecnológica, perda de mercados, ausência de capital de giro, dívidas frente a antigos proprietários e ausência de uma cultura de gestão por parte dos trabalhadores. O coletivo de trabalhadores tende a apresentar problemas de disciplina e falta de participação, favorecendo o surgimento de novas hierarquias baseadas na separação entre os trabalhadores que ocupam atividades administrativas e os que se ocupam da produção. Em níveis distintos, o mesmo ocorre em cooperativas originárias de outros formatos. Em pequenos empreendimentos cooperativos, a falta de capital, a quase impossibilidade ou, pelo menos, grande dificuldade de trabalhar com produtos próprios, a ausência de confiança entre os próprios trabalhadores e, em alguns casos, a manutenção da dependência de órgãos de incubação, são responsáveis pela alta mortalidade desses empreendimentos.

A cultura do trabalho, marcada pelo assalariamento, não favorece muito a participação democrática, já que parte dos trabalhadores considera que a gestão não é seu problema. Outra questão é que a subordinação, em grande medida, dessas cooperativas ao mercado competitivo, compromete sua autonomia pelas necessidades de adequação de padrões produtivos e formas de organização do trabalho similares a empresas regulares como forma de sobrevivência. A inserção em redes de terceirização, se por um lado pode favorecer sua viabilidade e permanência no mercado, por outro, reintroduz a subordinação desses trabalhadores, enquanto conjunto, aos 
ditames da empresa contratante, comprometendo sua existência enquanto proposta diferenciada de gestão da produção e do trabalho.

Entre os fatores apontados como condição de viabilidade desses empreendimentos coletivos, independentemente de sua orientação ideológica, é a capacidade empreendedora do grupo gestor, ou do coletivo gestor. Assim, a dimensão empreendedora é destacada não apenas no cooperativismo tradicional, historicamente identificado com uma perspectiva empresarial, mas do novo cooperativismo presente na proposta da economia solidária. Segundo Gaiger, a dimensão empreendedora seria indissociável da dimensão solidária dos empreendimentos. Isto porque potencializaria o esforço do coletivo de trabalhadores para lidar com as necessidades objetivas no cotidiano da produção, garantindo a sobrevivência do empreendimento e, dessa forma, beneficiando a todos. Não se constituiria em atitudes voltadas à criação de novos empresários competitivos inseridos no jogo do mercado capitalista, mas sim a um projeto comum ao coletivo. Dessa forma, "o empreendedorismo diz respeito à liderança e à gestão econômicas, capazes de produzir os resultados econômicos e as satisfações extra-econômicas intrínsecas aos empreendimentos" (2008, p. 62). Seria um empreendedorismo "brando" voltado à criatividade do coletivo para si mesmo (p. 70).

Em outros termos, a economia solidária teria de escapar de certa ilusão voluntarista que seria viável fora do mercado. A manutenção dos princípios solidários, em grande medida, garantiria a não-incorporação da lógica capitalista aos empreendimentos. Essa interpretação considera a determinação social da Economia o que implica no reconhecimento do mercado como inerente às sociedades humanas e seu funcionamento vinculado a valores, regras e distintas formas de relações sociais.

A questão de uma economia dos setores populares que teria automaticamente um caráter solidário é discutida por Coraggio (2000), refe- 
rindo-se à sua impossibilidade, uma vez inserida na sociedade capitalista. Caberia, então, a transformação da sociedade na qual coexistiriam formas distintas de produção. Nessa direção, as cooperativas se incluiriam em uma dessas formas, mas não a única. A economia dos setores populares teria, na unidade doméstica, seu fundamento. Singer (2000) contesta essa ideia afirmando que a produção simples de mercadoria, referência da unidade doméstica, integra o capitalismo em sua expressão rural e urbana, mas tem expressão menor na grande indústria na qual o assalariamento é dominante. As cooperativas representariam a superação capitalista, no sentido de que representariam empresas socialistas, igualitárias, democráticas, sem divisões de classe. Entretanto, a democracia na empresa é algo complexo, tal como demonstram as formas de degenerescência comum das cooperativas que se integram ao mercado capitalista, deixando de lado a perspectiva autogestionária, ou pelo menos, perdendo sua importância. Fica, contudo o paradoxo de como manter viável empreendimentos autogestionários no mercado capitalista, mantendo-os com princípios não capitalistas e solidários e, com isso, a viabilidade de outra economia, plural e democrática dentro do capitalismo.

\section{Empreendedorismo e cultura do trabalho}

Embora de forma distinta, a incorporação da ideia de empreendedorismo "brando", no caso das cooperativas e empresas autogestionárias, nos remete à afirmação de Machado da Silva (2003), referente à informalidade e à empregabilidade. Em que medida estaríamos falando a mesma coisa? Empreendedorismo como parte de uma nova cultura do trabalho?

A cultura do trabalho foi construída no século XX, a partir da centralidade do emprego assalariado e, a partir daí, a incorporação à relação salarial dos direitos sociais conquistados pelos trabalhadores integrantes 
das políticas reguladoras do Estado de bem estar social. Com a crise dos anos 70 e o avanço das políticas neoliberais, da revolução tecnológica e informacional, essa cultura do trabalho assalariado passou a ser questionada enquanto estruturante da vida dos trabalhadores, de seu pertencimento de classe e das possibilidades das transformações sociais. A grande fábrica deu lugar às unidades menores, possibilitada pela tecnologia, e as grandes concentrações de trabalhadores, em grande medida, têm sido substituídas por maior dispersão territorial. A globalização dos mercados e da produção provocou a desconcentração industrial nos países centrais, e novos territórios foram incorporados à produção. Os sindicatos perderam força com o aumento do desemprego estrutural e a redução de contingentes de trabalhadores. As bandeiras ideológicas unificadoras do movimento operário e dos trabalhadores sofreram um profundo baque: o fim do socialismo real.

Embora distintas, cultura do trabalho e cultura do assalariamento vinculam-se a uma forma de organização da produção marcada pela concentração de indústria e de trabalhadores. A cultura da fábrica e de fora de fábrica tiveram essa concentração como referência. Os bairros operários favoreciam a mobilização e as lutas dos trabalhadores, assim como marcavam a sociabilidade através dos bares, igrejas, associações, times de futebol e outras atividades que reforçavam no cotidiano as identidades sociais fundadas no trabalho. Mesmo com grande heterogeneidade, os bairros operários e de trabalhadores mantinham identidades forjadas na proximidade das condições de vida e trabalho, e a condição salarial aproximava as distintas categorias de trabalhadores. Um emprego era sinônimo de segurança e previsão de futuro, organizando a vida social.

Presente entre os trabalhadores, a informalidade era percebida como condição transitória a um emprego seguro, porta de entrada no espaço urbano para massas de migrantes rurais, estratégia de sobrevivência a perí- 
odos de desemprego, opção de trabalhadores (mulheres principalmente) a trabalhar em casa conforme idade dos filhos, enfim, algo eventual, delimitado no tempo. Entretanto, em países como o Brasil, essa transitoriedade sempre foi relativa e gerações de trabalhadores - principalmente em áreas menos industrializadas - nunca saíram da informalidade. Mesmo assim, a condição salarial ou uma cultura do assalariamento foi construída e incorporada por esses trabalhadores. Mesmo sem nunca terem tido sua carteira assinada, este era um objetivo a ser alcançado (LIMA; CONSERVA, 2004).

Estudos sobre "distritos industriais" informais no interior do país, como referenciado anteriormente, apontam para uma situação contraditória na qual existe uma tendência de secundarização do assalariamento pela possibilidade de trabalhar "por conta própria", dado o contexto de crescimento no qual multiplicam-se pequenos negócios e aumentam a possibilidade de êxito (LIMA; SOARES, 2002). Esse trabalhar-por-conta-própria passou a ser assimilado ao "empreendedorismo" dos anos 90, com políticas específicas de apoio e a formalização de pequenas empresas. Tornou-se política de Estado com os chamados "Arranjos Produtivos Locais" que buscam reduzir a informalidade e incentivar o empreendedorismo dos pequenos negócios através de formação para construção de um "espírito empreendedor" e políticas de apoio como incentivos fiscais diversos, simplificação e redução de impostos. Entretanto, embora afirmem preferir o trabalho autônomo, esses trabalhadores se ressentem dos "direitos" do assalariamento, uma segurança mais virtual do que real a que nunca tiveram acesso.

Esses distritos largamente informalizados e existentes em diversas regiões do país, terminaram por se beneficiar da reestruturação industrial, por produzir a custos baixos, competindo muitas vezes com os produtos "chineses" considerados imbatíveis. Fora destes pólos, entretanto, a redução dos empregos formais nos anos 90 e o incentivo governamental ao pequeno negócio como saída ao desemprego para trabalhadores 
desempregados de empresas privatizadas ou reestruturadas, revelou-se uma falácia, com várias tentativas frustradas de trabalhadores, buscando tornarem-se empreendedores.

Para os trabalhadores reestruturados ou ameaçados pela instabilidade dos contratos, empreendedorismo e empregabilidade juntam-se na lógica explicativa e justificadora, que atribui ao trabalhador a responsabilidade em sua permanência, ou não, no mercado de trabalho, assim como de sua reprodução social.

O mesmo ocorre com os processos autogestionários e formação de cooperativas. Estas, para sobreviverem e se apresentarem como modelos replicáveis, necessitam demonstrar viabilidade, o que pressupõe a adoção de modelos empresariais competitivos. É comum ouvir que não se pretende apenas organizar cooperativas de pobres e para pobres, mas organizar empreendimentos não apenas autogeridos, mas auto sustentáveis.

Algumas experiências espanholas têm sido acompanhadas com interesse no Brasil, como alternativas frente à redução do trabalho assalariado e suas possibilidades de replicação em outros contextos. Entre essas experiências destacam-se a organização sindical dos trabalhadores autônomos, as federações de cooperativas, as Sociedades Laborales, uma cooperativa mais flexível em sua organização em termos de número de membros e relação de propriedade ${ }^{13}$, e o paradigmático Complexo Cooperativo de Mondragón, considerado um exemplo de autogestão e inserção bem sucedida no mercado. O discurso democrático da autogestão, nesses casos, está mesclado ao da necessidade de um espírito empreendedor como forma de manter o empreendimento e torná-lo competitivo. Dirigentes dessas organizações destacaram a importância do espírito

13 As Sociedades Laborales são empresas privadas nas quais os trabalhadores devem ter pelo menos $51 \%$ do capital social e nenhum pode ter mais que $1 / 3$ das ações dessa empresa. É constituída por sócios trabalhadores, sócios não trabalhadores e trabalhadores assalariados. 
empreendedor presente na formação, inovação e competitividade como constituintes do empreendimento cooperativo ${ }^{14}$

O empreendedor, o trabalhador flexível e mesmo o cooperado, tornam-se figuras representativas do "novo" espírito do capitalismo. Cabe ao trabalhador internalizar os novos requisitos impostos pelo mercado. A realização pessoal e profissional e mesmo sua sobrevivência pessoal, cada vez mais depende disso. O futuro é incerto e manter-se no mercado exige grandes investimentos pessoais. A nova racionalidade capitalista considera o Estado provedor um elemento de atraso ao desenvolvimento pessoal, pois impediria a busca permanente pela empregabilidade e, por consequência, o espírito empreendedor. O individual se sobrepõe ao coletivo, mesmo quando o discurso é do coletivo. O coletivo exige uma configuração empreendedora que o sustente.

As novas ideologias organizacionais, que pressupõem a responsabilização crescente do trabalhador, resultam num autogerenciamento das subjetividades do trabalhador, no sentido de maior individualização. Isto, entretanto, mais (do) que produzir apenas consentimento no sentido da simples adesão a esses propósitos, na qual estaria excluída a possibilidade de resistência, pode possibilitar o que Zarifian (2002) define como engajamento subjetivo, no qual escolhas são possíveis. O trabalhador incorpora os novos valores empresariais até certo ponto, sem efetivamente deixar de perceber a exploração e os limites do discurso. Uma subordinação consentida não elimina a consciência do trabalhador acerca da precarização da vida e das possibilidades efetivas de reação e mesmo da ação coletiva.

Nas cooperativas de trabalhadores, mantém-se uma percepção da condição de trabalhador, mais do que a de trabalhador-proprietário. Nestas, a propriedade coletiva é secundarizada pela percepção do trabalho

14 Entrevistas realizadas em julho de 2008 pela equipe do projeto "Novas configurações do trabalho financiada pela Fapesp". 
coletivo como produto final e, com isso, tem-se uma reprodução da cultura do assalariamento, com incompreensões acerca do caráter diferenciado do empreendimento cooperativo. Em situações nas quais a percepção da condição de trabalhador proprietário é mais forte, nota-se maior propensão de uma compreensão do negócio e uma desvinculação com a noção de trabalhador assalariado, questionando pertinência da ação dos sindicatos na cooperativa. Estes, por sua vez, mesmo quando apoiam as cooperativas, ocasionalmente se dividem entre a defesa da cooperativa enquanto empreendimento e a defesa dos trabalhadores não associados das cooperativas, o que funciona como elemento complicador na relação trabalhador associado e trabalhador assalariado (LIMA, 2002, 2004, 2009).

\section{Concluindo}

No Brasil, o crescimento econômico a partir de 2002 implicou na redução da informalidade, e a recuperação de fábricas em situação falimentar e sua transformação em cooperativas, não se tem expandido. Por outro lado, aumentaram empreendimentos voltados à economia solidária em suas diversas manifestações. Estas, porém, voltadas mais à inclusão social de populações marginalizadas do processo produtivo do que efetivamente a formas alternativas ao assalariamento. Destacam-se também os investimentos no empreendedorismo por necessidade, a partir do apoio à pequena empresa e da formalização de atividades informais. Não houve uma reversão de tendências no sentido do aumento da proteção social vinculada ao assalariamento, mas tem crescido a formalização do trabalho, na qual o assalariamento continua referência. A precarização, entretanto, permanece justificada pela necessidade de redução de custos e, consequentemente, em aumento da competitividade. Esse assalariamento se distancia das formas anteriores dos direitos sociais acoplados e da maior 
proteção estatal, seja com a adoção de teorias organizacionais participacionistas, responsabilizando o trabalhador pela manutenção do emprego, seja com empregos com salários mais baixos de benefícios "enxutos" em greenfields distribuídos pelo país, nos quais, incentivos estatais garantem por um tempo, empreendimentos em determinadas cidades e regiões.

A nova crise iniciada no final do ano de 2008 pode apontar novas tendências no mercado de trabalho. Por enquanto, podemos trabalhar com hipóteses de expansão ou retração do assalariamento, dos ataques aos direitos dos trabalhadores e das possibilidades efetivas de resistência coletiva. Mas, como hipóteses. As mudanças no trabalho são irreversíveis, assim como a ética a ele vinculada. Mesmo assim, fica difícil falar de seu desaparecimento enquanto estruturante da vida social, ou mesmo do desaparecimento dessa ética. Talvez possamos afirmar sobre sua adequação aos "novos tempos", decorrente de um conjunto de situações, tais como as novas formas de inserção do mercado pelos trabalhadores; da maior ou menor interiorização dos valores da cultura empresarial; das formas de resistência que acompanham a fragmentação dos coletivos de trabalho; da dispersão dos contingentes de trabalhadores; das novas qualificações; das mudanças nas relações de trabaIho. Isso sem contar a questão dos direitos sociais que foram conquistados nas lutas dos trabalhadores e incorporados numa cultura de trabalho na qual o trabalho regulamentado, registrado, "com carteira" tornou-se um símbolo do acesso a esses direitos e de inclusão social.

Questões como individualização, autonomia, autocontrole, autogestão, e solidariedade compõem o chamado novo e precário mundo do trabalho, colocando novos desafios para a compreensão das possibilidades da ação coletiva, das identidades sociais e de uma cultura do trabalho que responde às transformações da cultura do capitalismo. As reinterpretações ou ressignificações de formas de organização do trabalho, originárias em contextos econômicos e políticos distintos, respondem a essas transformações. 
A maior individualização presente na cultura do trabalho da atual fase do capitalismo também deve ser relativizada, pois não elimina o caráter coletivo do trabalho enquanto atividade. Como também não elimina a percepção das condições de vida e trabalho semelhantes que acompanham os trabalhadores engajados em relações de trabalho assalariadas ou não assalariadas, assim como mantém projetos coletivos, embora ainda embrionários. Além disso, deve ser considerada a multiplicidade de situações de trabalho por ramo, setor de atividade, inserção no mercado, redes produtoras, de comercialização e distribuição, exportação, etc, que torna perigosa qualquer generalização acerca da percepção do trabalho.

No caso da autogestão, originalmente utilizada como proposta de autonomia dos trabalhadores, da gestão coletiva, de uma socialização efetiva da propriedade e gestão, o conceito agora é utilizado também como forma de auto-controle e responsabilização do trabalhador, de autonomia controlada para os interesses das empresas. O mesmo ocorre com o trabalho autônomo por necessidade na informalidade, na qual a viabilidade e a sobrevivência do trabalhador estarão vinculadas a seu espírito empreendedor.

Nas empresas recuperadas, ou cooperativas, na proposta da economia solidária, a viabilidade da autogestão se evidencia no empreendedorismo do coletivo e sua efetividade restringe-se ainda a um objetivo a ser alcançado, a partir da interiorização pelos trabalhadores, de que a gestão é uma questão a ser enfrentada para que essa autogestão exista. A discussão sobre o trabalho é sobreposta à discussão sobre a empresa. O trabalhador associado, em tese, é proprietário e, como tal, deve gerir seu empreendimento.

Em outros termos, o mercado aparece como a saída possível, seja capitalista ou não. Poderíamos então concluir com Sennet (2006), da substituição da sociedade do trabalho pela sociedade do consumo (na qual) as identidades seriam formadas no mercado? Nem tanto. Isso desconsideraria o caráter dinâmico das relações capital-trabalho e da própria 
cultura do capitalismo, marcada por conflitos e contradições entre as classes sociais.

Podemos considerar, talvez, que a incorporação da perspectiva empreendedora nas propostas coletivistas do movimento operário, na utilização de energias comuns adequadas às normas do mercado e a ele integradas, propõem, no atual debate sobre trabalho, um viés otimista como forma de driblar o "discurso único" que foi hegemônico nas últimas décadas nas quais a precarização das relações de trabalho e emprego estariam subordinadas e responderiam a uma necessidade "natural" da valorização do capital. Mais que simples consentimento, as propostas de integração plural, presentes nessas propostas, a coexistência de formas econômicas alternativas frente à crise dos projetos socialistas, poderiam ser vistas como resistências, ainda que embrionárias, às tendências precarizantes e ao discurso do fim do trabalho ou da sociedade salarial. Entretanto, esse fim é mais anunciado do que efetivo. Para os trabalhadores, a cultura do assalariamento representada pelos direitos sociais, ou a possibilidade de acesso a eles, marca profundamente a cultura do trabalho em seus aspectos relativos ao poder e autoridade e, enquanto tal, relativiza a incorporação dos valores do auto empreendimento e da autogestão.

Acreditamos que o conceito de cultura do trabalho, mesmo que impreciso em sua polissemia, auxilia no entendimento de como as transformações estruturais do capitalismo se articulam com as experiências cotidianas dos trabalhadores e as formas compartilhadas de percepção do mundo da vida e do trabalho; como os valores se interiorizam e se transformam; como o poder se reconfigura nas relações de trabalho, e como propostas e bandeiras de classe são ressignificadas. Constitui-se num espaço contraditório de compartilhamento de categorias e planos de ação, de consentimento e resistência, cuja compreensão é fundamental na análise da dinâmica social. 


\title{
Participation, Entrepreneurship and Self-Management: a new labor culture?
}

\begin{abstract}
This paper discusses the changes in the labor culture resulting from the flexibilization processes of the past decades, in which the emphasis on more work autonomy paradoxically has brought more subordination, under the umbrella of entrepreneurship. Thus, the article examines the idea of participation in companies and the use of self-control and self-management in work teams; the reinterpretation of informality as entrepreneurship, and the associated work in cooperatives under the umbrella of social entrepreneurship. The idea of participation and accountability, even in different organizational settings, represents a way for the workforce to obtain more autonomy and emancipation in the referential context of capitalism or any other economy, which would merge or coexist with different forms of production and property. This idea, with varying degrees, represents the beginning of a labor culture marked by the values of the so-called flexible capitalism: increasing individualization and the market as an indicator of the social relations.
\end{abstract}

Keywords: Entrepreneurship. Informality. Self-management. Solidarity economy. Labor culture.

\section{Referências}

ALENCAR, M. M. T. O apoio às pequenas unidades produtivas no Brasil: alternativa ao desemprego ou (dês) construção do trabalho assalariado no Brasil. In: FRANCISCO, E.M.V; ALMEIDA, C.C.L. Trabalho, território, cultura. Novos prismas para o debate das políticas públicas. São Paulo: Cortez, p. 99-118, 2007.

BARBOSA, Lívia. Cultura e empresas. Rio: Jorge Zahar Editor, 2002.

BATALHA, Claudio H. M; SILVA, Fernando Teixeira da; FORTES, Alexandre (Orgs.). Culturas de classe: identidade e diversidade na formação do operariado. Campinas: Editora da Unicamp, 2004.

BEAUD, Stéphane; PIALOUX, Michel. Retorno à condição operária: investigação em fábricas da Peugeot na França. São Paulo: Boitempo Editorial, 2009.

BECKER, Howard S. Outsiders. Estudos de sociologia do desvio. Rio de Janeiro: Zahar, 2009. 
BOLTANSKI, Luc; CHIAPELLO, Eve. O novo espírito do capitalismo. São Paulo: Editora WMF Martins Fontes, 2009.

BOUVIER, Pierre. Lê travail au quotidien. Une démarche sócio-anthropologique. Paris: PUF, 1989.

BRAGA, Ruy. A vingança de Braverman: o infotaylorismo como contratempo. In: ANTUNES, Ricardo; BRAGA, Ruy. Infoproletários: degradação real do trabalho virtual. São Paulo: Boitempo Editorial, 2009.

CAMARGO, José Márcio. Flexibilidade do mercado de trabalho no Brasil. Rio de Janeiro: Editora FGV, 1996.

CASTEL, Robert. As metamorfoses da questão social: uma crônica do salário. Petrópolis: Vozes, 1998.

CASTELLS, Manuel. A sociedade em rede. Rio de Janeiro: Paz e Terra, 1999.

COLBARI, Antonia. Ética do Trabalho. São Paulo: Letras e Letras, 1995.

CORAGGIO, José Luís. Da economia dos setores populares à economia do trabalho. In: KRAYCHETE, G.; LARA, F.; COSTA, B. (Orgs.). Economia dos setores populares: entre a realidade e a utopia. Petrópolis: Vozes, p. 91-131, 2000.

DE SOTO, Hernani. Economia subterrânea: uma análise da economia peruana. Rio de Janeiro: Globo, 1987.

GAIGER, Luiz Inácio. A dimensão empreendedora da economia solidária: notas para um debate necessário. Otra Economia, v. II, n. 3 - 2osestre de 2008. Disponível em: <http://www.riless.org/otraeconomia>. Acesso em: 19 dez. 2008.

GORZ, André. O imaterial: conhecimento, valor e capital. São Paulo: Annablume, 2005.

HARPER, Douglas; LAWSON, Helene M (Eds.). Introduction. In: The Cultural Study of Work. Lanham: Rowman \& Littlefield Publishers, Inc., p. xi-xviii, 2003.

HARVEY, David. Condição pós-moderna. São Paulo: Loyola, 1993.

HOBSBAWN, Eric J. Mundos do trabalho: novos estudos sobre história operária. Rio de Janeiro: Paz e Terra, 1987.

HOGGART, Richard. The Uses of Literacy. New Brunswick; London: Transaction Publishers, 1991.

HUGHES, E.C. Selected Papers on Work, Self and the Study of Society. v. 2. The Sociological Eye. Chicago: Aldine, 1972.

ITANI, Alice. Subterrâneos do trabalho: imaginário tecnológico no cotidiano. São Paulo: Hucitec, 1997. 
LEITE, Márcia de Paula. O trabalho no Brasil dos anos 2000: duas faces de um mesmo processo. Recife: Workshop - A Informalidade revisitada: das origens às novas abordagens, ABET, 2009.

LIMA, Jacob Carlos. As artimanhas da flexibilização: o trabalho terceirizado em cooperativas de produção. São Paulo: Terceira Margem, 2002.

. O trabalho autogestionário em cooperativas de produção: o paradigma revisitado. Revista Brasileira de Ciências Sociais, v. 56, p. 45-74, 2004.

. Paradoxos do trabalho associado. Tempo Social. Revista de Sociologia $\overline{\text { da USP }}$, 21(1), junho de 2009. p.113-132.

LIMA, Jacob Carlos; CONSERVA M. Redes sociais e mercado de trabalho: entre o formal e o informal. Política \& Trabalho, Revista de Ciências Sociais, João Pessoa, n. 24, p. 73-98, abril de 2006.

LIMA, Jacob Carlos; SOARES, Maria Jose. Trabalho flexível e informalidade. Caderno CRH, Salvador, Centro de Recursos Humanos da UFBA, n. 37, p. 163-80, jul/dez, 2002.

LIMA, Jacob Carlos; Ferreira, Brasília Carlos. Trabalhadores urbanos no Nordeste. Revista Brasileira de Ciências Sociais, v. 30, p.83-100, 1996.

LINHART, Robert. Greve na fábrica. Rio, Paz e Terra, 1986.

LOPES, José Sérgio Leite. A tecelagem dos conflitos de classe na cidade das chaminés. São Paulo: Marco Zero, 1988.

MACHADO DA SILVA, Luiz Antonio. Mercado de trabalho, ontem e hoje: informalidade e empregabilidade como categorias de entendimento. In: SANTANA, Marco Aurélio; RAMALHO, José Ricardo. Além da fábrica: trabalhadores, sindicatos e a nova questão social. São Paulo: Boitempo Editorial, p.140-178, 2003.

MARTINELLI, Alberto. O contexto do empreendedorismo. In: MARTES, A.C.B (Org). Redes e Sociologia Econômica. São Carlos: EdUFSCar, 2009.

MARX, K.; ENGELS, F. O manifesto comunista. São Paulo: Paz e Terra, 1996.

MAYO, Elton. The Social Problems of na Industrial Civilization. London: Routledge \& Kegan Paul LTD, 1952.

POLANYI, Karl. A grande transformação. As origens da nossa época. Rio de Janeiro: Editora Campus, 1980.

PORTES, Alejandro. The Informal Economy and Its Paradoxes. In: SMELSER, Neil J.; SWEDBERG (Eds.). The Handbook of Economic Sociology. Princeton, NJ: Princeton University Press, 1994. 
PORTES, Alejandro; CASTELLS, Manuel. World Underneath: The origins, Dynamics, and Effects of the Informal Economy. In: PORTES, Alejandro; CASTELLS, Manuel; BENTON, Lauren A. The Informal Economy. Studies in Advanced and Less Developed Countries. Baltimore, MA: The John Hopkins University Press, 1988.

RIBEIRO, Daniela. Trabalhadores da indústria de software: flexíveis e precários? Dissertação de mestrado (Sociologia). São Carlos, UFSCar, 2009.

ROSENFIED, Cinara Lerrer. A identidade no trabalho em call centers: a identidade provisória. In: ANTUNES, Ricardo; BRAGA, Ruy. Infoproletários: degradação real do trabalho virtual. São Paulo: Boitempo Editorial, 2009.

ROY, Donald. F. "Banana Time": Job Satisfation and Informal Interaction. In: HARPER, Douglas; LAWSON, Helene M. (Eds.). The Cultural Study of Work. Lanham: Rowman \& Littlefield Publishers, Inc., p.289-312, 2003.

SAVAGE, Mike. Classe e história do trabalho. In: BATALHA, Cláudio H.; SILVA, Fernando Teixeira; FORTES, Alexandre. Culturas de classe: identidade e diversidade na formação do operariado. Campinas: Editora Unicamp, 2004.

SCHUMPETER, Joseph A. Teoria do Desenvolvimento Econômico. Uma investigação sobre lucros, capital, crédito, juro e o ciclo econômico. São Paulo: Abril Cultural, 1982.

SENNETT, Richard. A cultura do novo capitalismo. Rio de Janeiro: Record, 2006.

SILVA, Fernando Teixeira da. Operários sem patrões. Os trabalhadores da cidade de Santos no entreguerras. Campinas: Editora Unicamp, 2003.

SINGER, Paul. Economia dos setores populares: propostas e desafios. In: KRAYCHETE, G.; LARA, F.; COSTA, B. (Orgs.). Economia dos setores populares: entre a realidade e a utopia. Petrópolis: Vozes, p. 143-161, 2000.

SOUSA LIMA, Ângela Maria de. As faces da subcontratação do trabalho: um estudo com trabalhadoras e trabalhadores da confecção de roupas de Cianorte e região. Tese (Doutorado em Ciências Sociais - Unicamp), Campinas, 2009.

TAYLOR, Frederick Winslow. Princípios de Administração Científica. São Paulo: Atlas, 1982.

TELLES, Vera S. Mutações no trabalho e experiência urbana. Tempo Social, Revista de Sociologia da USP, v. 18, n. 1, 2006.

THOMPSON, Eric Palmer. Costumes em comum. Estudos sobre a cultura popular tradicional. São Paulo: Companhia das Letras, 2008.

VENCO, Selma. Centrais de Atendimento: o surgimento dos colarinhos furtacores?. In: ANTUNES, Ricardo; BRAGA, Ruy. (Orgs.). Infoproletários: degradação real do trabalho virtual. São Paulo: Boitempo Editorial, v. 1, p. 8-252, 2009. 
WILLIAMS, Raymond. Cultura. Rio de Janeiro: Paz e Terra, 1992.

WILLIS, Paul. Aprendendo a ser trabalhador: escola, resistência e reprodução social. Porto Alegre: Artes Médicas, 1991.

ZARIFIAN, Philippe. Engajamento subjetivo, disciplina e controle. Novos Estudos CEBRAP, São Paulo, n. 64, p. 23-31, novembro 2002.

Recebido: $26 / 05 / 2010$

Aceite final: 08/09/2010 